\title{
Capsule Commentary on Lafreniere et al., Burned Out at the Bedside: Patient Perceptions of Physician Burnout in an Internal Medicine Resident Continuity Clinic
}

\author{
Kittu Jindal Garg, $M D^{1,2}$ \\ ${ }^{1}$ Cleveland Clinic Department of Community Internal Medicine, Cleveland, USA; ${ }^{2}$ Core Faculty, Cleveland Clinic Internal Medicine Residency \\ Program, Cleveland, USA.
}

J Gen Intern Med 31(2):225

DOI: $10.1007 / \mathrm{s} 11606-015-3550-9$

(c) Society of General Internal Medicine 2015

$\mathrm{L}$ afreniere et al. ${ }^{1}$ found that physicians with higher reported rates of depersonalization were perceived as more empathic and enabling by their patients. Also, higher physician emotional exhaustion scores did not significantly correlate with patient perceptions of empathy or enablement.

Internal medicine resident physician burnout is common, ${ }^{2}$ and has been the focus of many interventions over the past several years. The revamping of resident duty hour restrictions in 2011, among other goals, was implemented with the intention of limiting physician burnout and therefore improving quality of care provided to patients. ${ }^{3}$ Subsequent studies have shown that burnout did not significantly change after the 2011 duty hour restrictions were implemented, ${ }^{3}$ which makes this study by Lafreniere et al. ${ }^{1}$ all the more meaningful. As we continue to tweak duty hours and empower residency leadership to actively focus on reducing resident physician burnout rates, ${ }^{4}$ the intended outcomes may be years in the making, and it is important to consider whether resident perceptions of burnout are affecting their delivery of patient care. This study suggests that patients do not consider their burnt-out resident physicians to be providing them with inadequate care.

While minimizing burnout is important for residents' wellbeing, ${ }^{5}$ it is reassuring that patients' rating of empathy does not appear to be suffering, regardless of the degree of emotional exhaustion reported by resident physicians. ${ }^{1}$

Given the nature of the study, it is difficult to ascertain whether resident depersonalization is what is being perceived as empathic or enabling by the patient, or whether the strongly empathic residents are those that rate their own emotional exhaustion more critically. It would be useful to establish whether a causal relationship exists between residents reporting higher levels of depersonalization and being perceived as more enabling because they are, in fact, not as emotionally involved in the shared decision-making process, resulting in patient perceptions of increased enablement. Future research could help to establish causality, although this would be difficult given the inherent lability in perceptions of emotional delivery.

Corresponding Author: Kittu Jindal Garg, MD; Cleveland Clinic Department of Community Internal Medicine, Cleveland, USA (e-mail: jindal.kittu@gmail.com).

\section{Compliance with Ethical Standards:}

Conflict of Interest: The author has no conflicts of interest with this article.

\section{REFERENCES}

1. Lafreniere JP, Rios R, Packer H, Ghazarian S, Wrist SM, Levine R. Burned out at the bedside: patient perceptions of physician burnout in an internal medicine resident continuity clinic. J Gen Intern Med. 2015. doi: 10. 1007/s11606-015-3503-3.

2. West CP, Shanafelt TD, Kolars JC. Quality of life, burnout, educational debt, and medical knowledge among internal medicine resident. JAMA. 2011;306(9):952-60.

3. Ripp JA, Bellini L, Fallar R, Bazari H, Katz JT, Korenstein D. The impact of duty hours restrictions on job burnout in internal medicine residents: a three-institution comparison study. Acad Med. 2015;90(4):494-9.

4. Jennings ML, Slavin SJ. Resident wellness matters: optimizing resident education and wellness through the learning environment. Acad Med. 2015;90(9):1246-50.

5. Kassam A, Horton J, Shoimer I, Patten S. Predictors of well-being in resident physicians: a descriptive and psychometric study. J Grad Med Educ. 2015;7(1):70-4. 